\title{
O PROGRAMA DE SAÚDE ESCOLAR NO MUNICÍPIO DE RIBEIRÃO PRETO*
}

\author{
Maria das Graças Carvalho Ferriani** \\ Maria Aparecida Tedeschi Cano***
}

FERRIANI, M.G.C.; CANO, M.A.T. O programa de saúde escolar no município de Ribeirão Preto. Rev.latinoam.enfermagem, Ribeirão Preto, v. 7, n. 4, p. 29-38, outubro 1999.

O presente artigo relata a trajetória do Programa de Assistência Primária de Saúde Escolar (PROASE) no município de Ribeirão Preto e traz algumas reflexões sobre esta proposta.

UNITERMOS: saúde escolar, programa, educação em saúde

\section{A TRAJETÓRIA DO PROGRAMA NO PERÍODO DE 1985 A 1994}

O Programa de Saúde Escolar é coordenado por nós desde 1985 no município de Ribeirão Preto, em decorrência de um convênio firmado entre a Escola de Enfermagem de Ribeirão Preto da Universidade de São Paulo, Fundação de Assistência ao Estudante do Ministério da Educação (FAE) e a Prefeitura Municipal de Ribeirão Preto, tendo como intervenientes a Secretaria Municipal da Saúde. Suas ações vêm sendo realizadas por uma equipe multiprofissional (enfermeiro, pediatra, fonoaudiólogo, psicólogo, dentre outros), objetivando a prevenção e a promoção da saúde integral do escolar no município de Ribeirão Preto (FERRIANI \& CANO, 1992).

O PROASE inicialmente foi desenvolvido nas próprias escolas, mas com o passar do tempo, com a vivência e as discussões que foram emergindo no desenrolar do trabalho, passou a ter uma nova dimensão de suas atividades e como objetivo sair do espaço escolar, deixando aí apenas ações coletivas, as ações individuais e curativas deveriam estar centradas nas Unidades Básicas de Saúde (UBSs) e Unidades Básicas Distritais de Saúde (UBDSs). A coordenação do Programa e os profissionais têm muito claro que não se deve transformar as escolas em ambulatórios médicos, o que descaracteriza a escola enquanto espaço pedagógico. Outra questão a ser considerada é que o desenvolvimento desse trabalho no espaço escolar, no primeiro momento, foi necessário e oportuno, possibilitando aos profissionais entendimento dos reais problemas de caráter pedagógico, bem como da existência de crianças com necessidade de atendimentos especializados, que por outro lado, não contavam na rede com a hierarquização dos serviços para contemplar esse atendimento na estrutura das Unidades Distritais de Saúde.

Detectamos em Ribeirão Preto em 1987, que a cobertura de atendimento, nas Unidades Básicas de Saúde (UBS), para a faixa etária de cinco a catorze anos era pequena, não sendo satisfatória. As Unidades Básicas de Saúde (UBS), davam prioridade ao atendimento das crianças de zero a quatro anos, com ênfase nas de zero a dois anos. Sentimos ser necessário uma articulação entre a escola e o Serviço de Saúde para possibilitar uma maior cobertura em saúde a estas crianças. Portanto, era necessário uma organização do sistema de referência e contra-referência e os serviços de saúde da comunidade.

Outra questão levantada, se refere de que as ações em Saúde Escolar deveriam ocorrer como parte integrante da Atenção à Saúde da Criança e do Adolescente.

A criança em idade escolar, encontra-se excluída dessa programação, ficando marginalizada quanto aos cuidados de higiene e saúde. Visto que essa faixa etária apresenta menor índice de morbidade e menor possibilidade de adoecer. Considerando-se o problema mais freqüente dessa faixa etária os acidentes na infância.

\footnotetext{
* Este trabalho é parte da Tese de Livre-Docência de: FERRIANI, M.G.C. Percepções dos atores sociais que utilizam o Programa de Assistência Primária de Saúde Escolar — PROASE no município de Ribeirão Preto: análise crítica. Ribeirão Preto, 120p. Tese (Livre-Docência) - Escola de Enfermagem de Ribeirão Preto da Universidade de São Paulo

** Professora Doutora do Departamento de Enfermagem Materno-Infantil e Saúde Pública da Escola de Enfermagem de Ribeirão Preto da Universidade de São Paulo

*** Professora Associada do Departamento de Enfermagem Materno-Infantil e Saúde Pública da Escola de Enfermagem de Ribeirão Preto da Universidade de São Paulo
} 
Priorizando-se portanto, apenas a atenção à saúde da criança de zero a dois anos.

Todos esses pontos foram levantados e a coordenação do Programa de Assistência Primária de Saúde Escolar (PROASE) entendeu que deveria fazer uma proposta diferente para o atendimento do escolar no município de Ribeirão Preto. Certificamos, durante todos esses anos que deveria existir uma política transformadora em relação a esse atendimento do escolar, bem como dos outros segmentos da população infantil.

Com a mudança de Governo Municipal em 1989, foi assinado um convênio com a Escola de Enfermagem de Ribeirão Preto da Universidade de São Paulo (EERPUSP) e Prefeitura Municipal, tendo como intervenientes as Secretarias de Saúde e de Educação, uma vez que considerávamos importante o envolvimento articulado das duas secretarias, objetivando um trabalho multidisciplinar.

Nesta ocasião, a coordenação do PROASE recebeu a solicitação da Secretaria Municipal da Educação e da Secretaria Municipal da Saúde para que estudássemos a viabilidade técnica de expandir o atendimento do Programa para todas as Escolas Municipais de Educação Infantil de Ribeirão Preto EMEIs que recebem crianças na faixa etária de quatro a seis anos de idade, mesmo considerando que naquele momento a Prefeitura não poderia contratar novos profissionais. Visitamos todas as EMEIs e elaboramos um projeto que foi encaminhado aos dois Secretários Saúde e Educação.

Encontramos uma clientela diferenciada em comparação com as crianças de $1^{\circ}$ grau, com características e necessidades diferentes. A proposta se pautou em desenvolver condições para uma melhor atenção ao crescimento da criança, com um aperfeiçoamento do preparo dos professores da pré-escola (pela Educação), propondo situações que favoreçam o desenvolvimento, com execução de atividades de prevenção de problemas. Outro ponto a ser destacado era que quase todas as EMEIs estavam localizadas próximas as UBSs e a coordenação do PROASE ativou a sua proposta de que essas crianças deveriam ser atendidas nas UBSs juntamente com as crianças em idade escolar, considerando que a população de quatro a seis anos que freqüenta EMEIs corresponde à pequena parcela do número total de crianças dessa faixa etária em Ribeirão Preto. Considerando também que, uma parte desses alunos conta com o atendimento médico-odontológico, podemos afirmar que, em tese, a demanda seria absorvida pela rede de Saúde Pública, sem necessidade de contratações de médicos com o fim específico de atendimento a crianças pré-escolares e escolares.

Nessas negociações com o novo Governo Municipal, sentimos que não fomos ao encontro da política traçada pela Educação, uma vez que estávamos querendo sair das escolas e ir para as Unidades Básicas de Saúde (UBS). A expectativa da Educação era para um atendimento dos profissionais mais dirigido às crianças que freqüentavam as EMEIs e as Escolas de $1^{\circ}$ grau da rede municipal, concentrando todos os esforços do Programa a essas crianças da rede municipal.

Indubitavelmente, esses pontos eram contraditórios, uma vez que o nosso trabalho era desenvolvido naquela ocasião com escolas, tanto da rede Municipal como da rede Estadual, perfazendo um total de 28 escolas e com um quadro de recursos humanos correspondente a 28 profissionais.

A nossa intenção era contemplar mais escolas e beneficiar mais crianças dessa faixa etária, sem a preocupação de ser da rede municipal ou estadual, tendo como eixo central a "Criança em Idade Escolar" do município de Ribeirão Preto, uma vez que não havia possibilidade de integração naquele momento com o Programa da Criança, da Secretaria Municipal da Saúde de Ribeirão Preto.

A saída dos profissionais do PROASE da escola em 1991, para as Unidades Básicas Distritais de Saúde (UBDS) (psicólogo, fonoaudiólogo, pediatra, dentre outros) objetivava o atendimento especializado somente às crianças que necessitassem, considerando que não se contava na rede com este tipo de atendimento. Por não contar com serviços especializados, o PROASE se propôs a dar esse atendimento com uma visão mais ampla desta questão, procurando discernir os problemas de caráter pedagógico que são da educação, dos problemas de saúde que podem efetivamente comprometer o desempenho da criança na escola. Tínhamos claro, que o PROASE não conseguiria resolver na totalidade os problemas, uma vez que estes são bastante complexos. Entendíamos que na UBS essas crianças tinham o mesmo direito à saúde como qualquer outro segmento da população. Não havia necessidade, portanto, de continuarmos dentro das escolas com toda uma estrutura de saúde para atendimento, pois Ribeirão Preto constitui-se em um grande centro de referência de atenção à saúde em nível regional.

Com essa nova organização no município de Ribeirão Preto, o PROASE em 1991 se reestruturou e se expandiu colocando em prática a sua proposta feita ao novo Governo e implantou quatro ambulatórios de Saúde Escolar, um em cada Distrital e um no Centro de Saúde Escola (Sumarezinho), com os recursos humanos já existentes, objetivando atender crianças com necessidade de atendimentos especializados (fonoaudiologia, psicologia, dentre outros), pois naquele momento a rede não contava com serviços desse porte conforme já mencionamos.

O município em 1992 possuía onze hospitais sendo dois públicos (Hospital das Clínicas e Hospital 
Psiquiátrico), nove privados e filantrópicos. Além dos hospitais, a cidade contava com um vasto número de consultórios médicos, odontológicos, clínicas especializadas, laboratórios de análises clínicas, serviços de radiologia e equipamentos hospitalares.

Nesse período, em relação aos serviços de Saúde Pública, o município contava com vinte e oito Unidades Básicas de Saúde (UBS) e entre essas estão as Unidades Municipais e Municipalizadas, e três Unidades do Centro de Saúde Escola. Essas Unidades constituem a rede básica de serviços, organizadas de forma a serem a "porta de entrada" do Sistema de Saúde, seguindo os princípios de regionalização e hierarquização.

No município, a rede básica já nesse período, estava subdividida em áreas geográficas, delimitando a abrangência de atendimento à população, organizada administrativamente em Distritos Sanitários. Em 1992, existiam quatro Unidades Distritais de Saúde (Central, Vila Mariana, Simioni e Vila Virgínia). Estes distritos determinam o número de Unidades Básicas de Saúde (UBS) e escolas em suas regiões, que se constituem em referência para atendimento em algumas especialidades. A indicação em termos de complexidade do atendimento, era basicamente, realizada pelo Ambulatório Regional de Especialidades (ARE) e pelos hospitais; alguns atendimentos também eram realizados no Centro de Saúde Escola-Sumarezinho (CSE).

Como a rede de saúde não conseguiu implantar nas UBDSs as especialidades de oftalmologia e otorrinolaringologia, em função dos custos operacionais, foi montado em 1992 uma Unidade de Referência do PROASE com essas especialidades para o atendimento dos escolares de toda a rede pública de ensino.

Este atendimento foi possível, devido ao projeto encaminhado em outubro de 1990 solicitando à FAE a implantação de um Laboratório Óptico para o programa, em decorrência dos problemas vivenciados no que se refere aos distúrbios visuais e a dificuldade de aquisição de óculos pela famílias dos alunos. Este projeto foi aprovado e, posteriormente, assinado um convênio com a EERP-USP em setembro de 1991. Com a decorrente aprovação do projeto, a FAE nos forneceu lentes, armações e uma máquina para a montagem de óculos. A EERP-USP conseguiu um local no Campus-Ribeirão Preto para que fosse montado o Laboratório Óptico do PROASE e aproveitamos dois auxiliares de enfermagem do Programa que foram treinados pelo próprio pessoal da FAE, através de um curso de quinze dias em Belo Horizonte/MG. Este Laboratório Óptico, vem atendendo às necessidades da comunidade escolar de Ribeirão Preto, e é Centro de Referência para cinqüenta municípios do Estado de São Paulo conveniados com a FAE, onde os óculos dessas cidades são confeccionados. Em 1994, a Escola de Enfermagem de Ribeirão Preto da Universidade de São Paulo concordou em assinar um termo aditivo de convênio para ser referência para setenta e cinco (75) municípios que são conveniados com a FAE.

É importante ressaltar que para as crianças com problemas especiais necessitando de atendimento educacional técnico-pedagógico e alunos portadores de necessidades especiais quer física, mental e/ou sensorial, a Secretaria Municipal de Educação, criou uma Escola de Educação Especial para atender a esta população. Os profissionais das áreas de psicologia, fonoaudiologia, fisioterapia, terapia ocupacional, dentre outros, que atuam nessa Escola ficaram vinculados ao PROASE, uma vez que no organograma da Secretaria Municipal da Saúde não existia Departamentos específicos de cada área, mas o projeto de atendimento a essas crianças é da responsabilidade da própria Secretaria Municipal da Educação e da escola.

Em 1993, com a mudança de governo dentre as novas diretrizes políticas traçadas para os quatro anos, culminou em novas propostas das duas Secretarias, que diretamente o PROASE está trabalhando - Saúde e Educação. O Programa passa a ser questionado pela sua verticalidade e por ser um Programa estanque voltado para uma faixa etária específica.

Conforme já mencionamos anteriormente, foi designado um coordenador para a área da Saúde da Criança e do Adolescente para o município e formado um grupo de trabalho para discutir a situação da saúde da criança e do adolescente e a partir daí, elaborar propostas de ação. Passamos a fazer parte do grupo, objetivando uma integração e entendendo que este seria o momento de ser colocado em prática, que atenção à criança em idade escolar e ao adolescente no município de Ribeirão Preto deveria ser um Programa único. Dessa forma, as nossas propostas vêm de encontro à política do novo governo, visando uma integração dos Programas. Assim, a criança em idade escolar e o adolescente, devem ser contemplados por uma Política de Atenção à Saúde da População.

Entretanto, apreendemos ao longo desses três Governos, que não é suficiente o conhecimento técnicocientífico, para que se possa transformar o discurso teórico em prática, pois outras questões extrapolam o nosso conhecimento, no caso a política e o poder. Temos claro que, para o estabelecimento de uma política de saúde, é necessário uma mudança na qual se assuma uma proposta política transformadora para todos os segmentos da sociedade.

No período de janeiro de 1993 a setembro de 1994, através da Secretaria Municipal de Saúde, o PROASE buscou uma maior integração com o grupo responsável pela elaboração de uma proposta para a Saúde da Criança no município, assim como, com os novos Programas que estavam sendo implantados: Saúde da 
Mulher e Saúde Mental. Um dos resultados dessa integração foi, em junho de 1994, a organização e implantação do "Recanto do Adolescente", uma casa localizada em bairro carente da periferia da cidade, onde jovens de 11 a 18 anos se reúnem para discutir com os profissionais dos Programas ou outros convidados, questões relativas à adolescência. O Recanto do Adolescente associa atividades educativas e de lazer através de filmes, jogos, músicas e brincadeiras. Embora as atividades estejam programadas para serem desenvolvidas durante toda a semana, é aos sábados que um contingente maior de jovens comparece, composto principalmente por aqueles que trabalham. Dessa forma, busca-se preparar o jovem para uma vida mais saudável.

Uma outra integração do PROASE se deu com a Unidade Básica e Distrital de Saúde Central, na elaboração e implantação gradativa do ambulatório especializado de otorrino e fonoaudiologia para atendimento de crianças portadoras de fissura lábiopalatal e deficiência auditiva. Este ambulatório tem, entre outros, o objetivo de detectar, o mais precocemente possível, as crianças portadoras dessas patologias através de hospitais, escolas e profissionais dessas áreas. Este acompanhamento se realiza através de terapia específica de reabilitação com os portadores dessas patologias, mantendo vínculos com o Hospital de Reabilitação de Bauru/SP, Hospital das Clínicas de Ribeirão Preto e Santa Casa, para o acompanhamento de crianças do nosso município que receberam correção cirúrgica de palato e lábio nesses hospitais. Objetiva ainda, organizar grupos de discussão e orientação com os pais, trabalhar em conjunto com profissionais da área que atuam no Centro de Educação Especial "Egydio Pedreschi" da Secretaria Municipal da Educação e nas Unidades Básicas e Distritais de Saúde de Ribeirão Preto.

Fora do ambiente da Secretaria Municipal de Saúde, o PROASE vem se integrando ao "Programa Ribeirão Criança", ligado diretamente à Prefeitura Municipal de Ribeirão Preto. Esse Programa reúne profissionais das diferentes Secretarias Municipais, Entidades da Comunidade, Universidade e pessoas interessadas em desenvolver atividades no âmbito desses programas. O PROASE está atuando mais diretamente junto aos sub Programas: "Jovem Ribeirão" e ao "Ação pela Criança e Adolescente Dependente de Drogas (APCAD)". O primeiro, é um trabalho educativo para adolescentes, que aproveita datas comemorativas do calendário como "dia dos namorados", "dia do estudante", "semana da criança" entre outros para desenvolver atividades nas praças da cidade ou nas escolas. Seus temas básicos são sexualidade, Síndrome da Imunodeficiência Adquirida (AIDS) e Doenças Sexualmente Transmissíveis (DST), além de assuntos de interesse dos jovens como por exemplo animais peçonhentos, fitoterapia, ecologia, entre outros

Com relação ao APCAD, o grupo de profissionais se reúne regularmente a cada 15 dias. Foi realizado um Seminário com o objetivo de levantar as necessidades do município no que se refere à drogadição de crianças e jovens e criar estratégias de ação mais viáveis às nossas necessidades e congregar entidades e Programas Governamentais ou não, que já atuam de maneira paralela ou isolada nessa área.

Pensamos que essas integrações do PROASE fora da Secretaria Municipal de Saúde contribui não só para ampliação do seu campo de ação, fora do espaço escolar e das próprias Unidades Básicas e Distritais de Saúde (UBDS), como também na aquisição de novos conhecimentos e troca de experiências.

Embora ocorrendo todas essas mudanças no PROASE, temos claro que deve haver uma integração maior com a Educação, principalmente em nível de município, para um trabalho interdisciplinar, para tanto é necessário conhecermos melhor as propostas atuais dessa área, para que possamos definir os nossos campos de atuação.

\section{ALGUMAS REFLEXÕES SOBRE A TRAJETÓRIA DO PROASE NO MUNICÍPIO DE RIBEIRÃO PRETO}

Compreender todas estas questões, exige de certa forma recuperar a história neste passado mais recente do setor saúde, não no sentido restrito da revolução histórica, mas na tentativa de trazer os determinantes presentes no processo.

Assim, para uma compreensão da trajetória do PROASE no município de Ribeirão Preto, é necessário também que se traga alguns estudos recentes sobre Programas de Saúde Escolar em geral.

Em estudo anterior, FERRIANI (1991) analisou criticamente a inserção do enfermeiro na Saúde Escolar como objetivo central, bem como, demonstrou o desenvolvimento de uma prática escolar. Nesta, uma reflexão crítica desenvolveu a construção de uma consciência teórica sobre o papel técnico e social que cabe ao profissional de saúde.

Fundamentando nesta investigação e em outros estudos e, na nossa experiência diária, detectamos uma limitação na atuação da enfermagem e de outros profissionais relativa à assistência específica ao escolar, em especial aos de condições sócio-econômicas precárias. O conhecimento ainda é superficial. Quando se fala em Saúde Escolar, depara-se com a problemática da visão, audição e dentição.

LIMA (1986), analisando dezoito projetos 
financiados pela Fundação de Assistência ao Estudante (FAE), relata a diversidade de concepção sobre a saúde escolar com um grande descompasso de formas entre os projetos. Observou, como erros fundamentais, a tentativa de barateamento ao extremo da execução de projetos e a ênfase que alguns projetos pretendem dar à educação em saúde, em detrimento a ações objetivas em relação a problemas de solução já equacionados.

Em outro estudo (FERRIANI et al., 1990) analisam 21 (vinte e um) Programas financiados pela FAE em 1988, e observam a presença de uma assistência fragmentada, com utilização de pessoal mal preparado, desprovido de uma estrutura e de uma avaliação sistematizada.

Outra questão é que as ações dos Programas de Saúde Escolar têm sido desenvolvidas para a população que freqüenta a escola, partindo-se do pressuposto que existem condições de acesso universal e igualdades de oportunidades no processo de escolarização. Entretanto, o que ocorre na prática é que milhares de crianças se encontram fora do sistema educacional, seja porque não entram, seja porque se evadiram da escola. Esta seleção de clientela a ser atendida acaba realizando uma dupla exclusão: a criança excluída da escola, fica por conseguinte, excluída do direito à assistência de saúde.

Se o escolar for pobre, a relação fracasso escolar e desnutrição é imediata e mecânica. E mais, em se tratando de Saúde Escolar já se tem como pressuposto que se está falando de doença, porque essas crianças não conseguem aprender. Tal limitação nos mostrou a necessidade de aprofundarmos os conhecimentos de saúde destas crianças entendendo a fusão do biológico com o social.

Temos observado que os escolares e os adolescentes têm os mesmos determinantes de saúde da população, com um perfil bastante semelhante. As crianças em idade escolar necessitam de um sistema de saúde que lhes garanta o direito à promoção, conservação e reparação. Em decorrência aos altos índices de mortalidade infantil em nosso país, o setor saúde tem priorizado os Programas de Assistência Materno-Infantil. A mortalidade na faixa etária do escolar é baixa, sendo os acidentes a principal causa de morte.

HARADA (1993) chama a atenção em seu estudo para o exame clínico realizado no ingressante em seu Programa de Saúde Escolar na cidade de Embu-SP, onde apresenta uma elevada taxa de morbidade, com alta prevalência de doenças infecto-parasitárias típica de comunidades de baixo nível sócio-econômico. Observou também a presença de alterações de etiologia congênita e do grupo de doenças endócrinas, metabólicas, nutricionais e imunológicas, sendo que muitas destas alterações poderiam ter sido diagnosticadas mais precocemente. A saúde e a educação muitas vezes querem tratar o fracasso escolar como uma doença, através de ferramentas que não são capazes de reverter o quadro, problema com o qual, a realidade brasileira vem convivendo há anos. Observamos que desse quadro de alterações há outros aspectos que extrapolam estas duas práticas sociais, ou seja, Saúde e Educação.

PATTO (1990), preocupada com a Produção do Fracasso Escolar, faz uma revisão na literatura sobre as causas das desigualdades educacionais na sociedade brasileira e uma análise das raízes históricas das concepções sobre o fracasso escolar das crianças dos segmentos mais pobres da população.

Complementa sua pesquisa com observações em vários contextos e entrevistas formais e informais com todos os envolvidos no processo educativo que se desenrola numa escola de $1^{\circ}$ grau: a escola que não aceita a criança como é e a criança que não aceita a escola como funciona. A autora chama atenção entre as conclusões ou confirmações que o estudo permitiu destacando quatro aspectos, pelo caráter fundamental de que se revestem:

1. As explicações do fracasso escolar baseadas nas teorias do déficit e da diferença cultural precisam ser vistas a partir do conhecimento dos mecanismos escolares produtores de dificuldades de aprendizagem.

2. O fracasso da escola pública elementar éo resultado inevitável de um sistema educacional gerador de obstáculos a realização de seus objetivos.

3. O fracasso da escola elementar é administrado por um discurso científico que estudado em sua competência, naturaliza esse fracasso aos olhos de todos os envolvidos no processo.

4. A convivência de mecanismos de neutralização dos conflitos com manifestações de insatisfação e rebeldia faz da escola um lugar propício à passagem ao compromisso humano genérico.

COLLARES \& MOYSES (1992), ressaltaram a importância do fator pedagógico como determinante no processo do fracasso escolar, na medida em que ele está vinculado a fatores internos da instituição escolar como formação profissional, o planejamento do ano letivo, a inadequação curricular e a metodologia do processo de ensino-aprendizagem.

O setor da saúde não pode buscar a resolução dos problemas de aprendizagem através de um modelo clínico tradicional, individual e biológico, com conseqüente medicalização desta questão, pois desta forma, tenta-se localizar o problema exclusivamente na criança, explicando-o através de relações lineares e simplistas da ocorrência de doenças, isentando as responsabilidades do sistema educacional e da sociedade. 
HARADA (1993) constatou também que o perfil de morbidade encontrado entre as crianças encaminhadas pela equipe de saúde foram alterações predominantemente orgânicas, enquanto que os quadros de cefaléia, distúrbios de aprendizagem, comportamento, linguagem escrita compuseram uma parcela importante do perfil de morbidade dos casos encaminhados pelos professores, demonstrando dessa forma uma diferença desses encaminhamentos entre os profissionais da área de saúde e da educação.

Para melhor compreensão dessas questões levantadas na literatura específica sobre a Saúde Escolar é necessário que se traga os serviços de saúde na perspectiva do Sistema Único de Saúde (SUS).

O setor saúde na década de 70 foi reestruturado ao deflagrar-se nova crise no sistema capitalista, criandose o Sistema Nacional de Saúde (Lei 6299/75), visando à ampliação de suas bases sociais e ao atendimento das reivindicações populares.

O Estado brasileiro, através do Ministério da Saúde, incentiva a criação de Programas de Extensão de Cobertura, dirigidos aos setores mais carentes da população, como Programas de Alimentação e Nutrição, Vigilância Epidemiológica e Saúde Materno-Infantil (SILVA,1986).

É importante ressaltarmos que, como fruto da Reforma Administrativa da Secretaria de Estado de Saúde de São Paulo, tem-se a implantação de um novo modelo de organização tecnológica de trabalho na Saúde Pública Paulista, denominado Programa em Saúde (NEMES, 1990).

Vários autores, a exemplo de SCHRAIBER (1990) e CAMPOS (1989), vêm discutindo as questões da programação em saúde. Este modelo de programação tem como características marcantes a centralização normativa, descentralização executiva, sistema de informação e os Centros de Saúde como Unidades responsáveis pelos problemas de Saúde Pública da Comunidade. Outra relevante característica é o desenvolvimento e ampliação da assistência médica individual, prestada pela Secretaria Estadual da Saúde de São Paulo.

Portanto, desde a década de 70 foram formulados os Programas de Saúde. Data de 1974 a criação do Programa de Saúde Materno Infantil do Ministério da Saúde, cujo objetivo principal era a redução da morbidade e da mortalidade do grupo materno-infantil. Entretanto, embora a faixa etária de 7-14 anos estivesse contemplada no discurso na prática ela não ocorria.

Cabe chamar a atenção para as características tecnológicas deste modelo programático que apontam para uma diversificação de agentes envolvidos no processo de trabalho, acentuando a divisão técnica do trabalho. Nos serviços de atenção primária, o atendimento era especificado em pré-consulta, consulta médica, pósconsulta. As principais atividades desenvolvidas eram vacinação, atendimento de enfermagem, visita domiciliária, convocação de faltosos, controle de comunicantes, familiares e identificação de grupos de risco.

A partir do início da década de 80 , o modelo programático, vai perdendo espaço, em decorrência do restrito aporte de recursos financeiros destinados à Saúde Pública, o que acaba por limitar os recursos humanos e materiais. Dessa forma, com a crise econômica, a demanda sem acesso aos Serviços de Saúde começa a buscar assistência nos Centros de Saúde, o que permitiu a ampliação da Assistência Médica Individual, dando espaço para o atendimento de indivíduos doentes, sendo esse fato considerado como aquele que diferencia esse modelo de saúde dos anteriores no Estado de São Paulo.

Os aspectos principais do Programa de Assistência à Criança, consistiam no acompanhamento do processo de crescimento e desenvolvimento; combate à desnutrição e o combate às doenças preveníveis por imunização. Em decorrência das mudanças ocorridas no setor saúde, houve várias reformulações após o Programa da Criança de 1974, principalmente na década de 80 .

Em 1984, o Ministério da Saúde definiu as ações básicas para Assistência Integral à Saúde da Criança com vistas à população de menores de cinco anos de idade, com a meta de reduzir a morbi-mortalidade nesta faixa etária, tendo como objetivos específicos:

- O acompanhamento do crescimento e desenvolvimento; - $O$ aleitamento materno e orientação alimentar para o desmame;

- A imunização;

- A assistência e controle das infecções respiratórias agudas;

- O controle das doenças diarréicas.

Essas ações foram embasadas nas políticas de expansão e consolidação da Rede de Serviços Básicos, originadas na proposta da Atenção Primária à Saúde, cujos princípios foram difundidos em níveis internacional e nacional, sendo base para a organização do Sistema de Saúde no Brasil, em direção à municipalização.

Segundo TANAKA (1991), no Estado de São Paulo, até o final de 1984, o convênio Ações Integradas de Saúde (AIS) já havia sido assinado por 353 municípios paulistas, evidenciando-se o emergente papel do município como responsável pela prestação de Serviços da Saúde.

Em 1986, houve um grande marco na Saúde no Brasil, quando aconteceu a $8^{\text {a }}$ Conferência Nacional de Saúde, onde os temas básicos foram: "A Saúde como direito de todos e dever do Estado" e "A Reorganização do Sistema Financeiro do Setor Saúde". Nas discussões foi proposto a criação de um Sistema Único de Saúde, 
através da Reforma Sanitária, fundamentada nos princípios de universalização, na gestão única dos serviços, regionalização e hierarquização das unidades prestadoras de serviços e na participação da população no controle social dos serviços e fortalecimento do papel do município (CONFERÊNCIA NACIONAL DE SAÚDE, 1996).

Em 1990, o Sistema Unificado e Descentralizado de Saúde, baseado no texto constitucional de 1988 passou a ser denominado Sistema Único de Saúde (SUS) que contempla novamente a descentralização com direção única em cada esfera do governo, o atendimento integral e a participação da comunidade, entre outros pontos (BRASIL, 1988).

Nesse período, ocorre na rede básica uma proposta de aumentar o volume de assistência médica, como uma forma de substituição de uma parte dessa assistência prestada pela previdência e pela medicina privada, conveniada em nível ambulatorial.

Segundo SCHRAIBER (1990) esta proposta configurou-se no "Modelo Assistencial", suscitando críticas ao modelo da programação. Essas censuras enfatizavam que os programas eram burocráticos, tradicionais e inadequados às diferentes realidades do país.

A este respeito MERHY (1989): “A base tecnológica do modelo assistencial (SUDS-AIS) é o da Assistência Médica que entende uma hierarquia de enfrentamento dos processos coletivos das doenças, através de um pronto-atendimento como primeira ação, a partir da qual sobram os casos a serem enfrentados por uma ação mais instrumentalizada tecnologicamente". Há uma "medicina de queixa conduta", prestada pelo setor público à maioria da população e, por trás, a "verdadeira medicina", com articulações entre público e privado e altos investimentos tecnológicos.

Esses movimentos também ocorreram no município de Ribeirão Preto. Em 26 de abril de 1984, A Lei $\mathrm{n}^{\circ} 4.476$ autoriza a Prefeitura Municipal a implantar e executar o Programa de Ações Integradas de Saúde, preconizado nas diretrizes de ações do Ministério da Saúde. A referida lei propõe a reorganização da rede pública de serviços no município, compreendida pela Secretaria Estadual da Saúde, Secretaria Municipal de Ribeirão Preto e os serviços próprios do Instituto Nacional de Assistência Médica e Previdência Social, de modo a viabilizar um Sistema Municipal de Saúde Integrado, regionalizado e hierarquizado com possibilidades de cobertura universal em sua expansão (RIBEIRÃO PRETO, 1994).

Segundo o documento "Proposta de Reestruturação de Unidades de Saúde", a constituição e organização das Unidades Básicas de Saúde, deveriam funcionar como porta de entrada ao Sistema de Saúde, constituindo portanto, um atendimento universal e integral, quebrando a dicotomia preventivo-curativo, ou seja, destinado a todo e qualquer cidadão, independente de ser previdenciário ou não, com um grau de resolutividade de $80 \%$ dos problemas de saúde de uma determinada área de abrangência. A proposta deveria estar integrada a um sistema hierarquizado, de forma a possibilitar a referência de casos às unidades de níveis mais complexos do sistema, e a contra-referência para continuidade de atenção no local, contando com a retaguarda laboratorial e fornecimento gratuito de medicação (RIBEIRÃO PRETO, 1986).

Segundo MISHIMA et al. (1990), no período compreendido entre 1984-1987, no município de Ribeirão Preto, houve um aumento significativo de Unidades de Saúde no âmbito municipal, representando um crescimento de 46,6\%. Quanto aos recursos humanos, houve um crescimento da ordem de $30,7 \%$ no nível universitário, $15,5 \%$ para nível médio e 36,5\% no nível elementar do subsetor público e, quanto ao pessoal de enfermagem, a categoria dos enfermeiros foi a que mais cresceu num total de $210 \%$.

A Secretaria da Saúde contava naquela época com 11 Postos de Atendimento Médico (PAM) e a partir de 1986 foi definida a construção de novas Unidades de Saúde, a contratação de recursos humanos, a implantação de Sistema de Arquivos e Prontuários de Pacientes, a retaguarda ambulatorial e de Raio $\mathrm{X}$, entre outros (ALMEIDA,1991).

O município de Ribeirão Preto, em 1987, através da Lei $\mathrm{n}^{0} 5.194$ estabeleceu o convênio de Municipalização, dando seguimento ao Programa de Desenvolvimento do Sistema Unificado e Descentralizado de Saúde dos Estados (SUDS). Proveio desse Programa o repasse de verbas públicas do Estado para o nível local, ficando o gerenciamento da saúde sob a responsabilidade do município. Assim, nesse processo de municipalização a rede pública de serviços se reestruturou, tendo em 1990 um total de 26 Unidades Básicas de Saúde.

Em 1989, foi oficializada a proposta dos Distritos, implicando na divisão didática do município em grandes áreas geográficas, onde se teria uma Unidade Básica e Distrital de Saúde abrangendo várias Unidades Básicas de Saúde responsáveis pelo atendimento básico para a população usuária de sua área de abrangência. A UBDS seria referência em atendimento emergencial para todo o distrito, assim como ofereceria especialidades de alta demanda em nível ambulatorial como: oftalmologia, dermatologia, pneumologia, ginecologia, cardiologia e outros, como também exames de radiologia simples, ultrasonografia e eletrocardiografia. Entretanto, embora fosse esta a proposta, as UBDSs estão funcionando atualmente 
como unidades administrativas regionais, referências para algumas especialidades.

No Plano Diretor de Saúde do Município, elaborado pela Secretaria Municipal da Saúde, o Programa de Assistência Integral à Saúde da Criança, objetivava "a promoção da saúde na infância, visando a diminuição dos índices de mortalidade infantil, da desnutrição e incidência de doenças infecto-contagiosas e preveníveis por vacinação". O Programa propõe ainda abranger ações preventivas, educativas, curativas, como também as ações básicas já preconizadas pelo Ministério da Saúde como: vigilância do crescimento e desenvolvimento pondo-estatural; imunizações; aleitamento materno e suplementação alimentar; controle de doenças diarréicas com terapia de reidratação oral; controle das doenças respiratórias da infância (RIBEIRÃO PRETO, 1991).

Trazendo o estudo de ALMEIDA (1991), realizado neste período do processo de municipalização em andamento no município de Ribeirão Preto, depreendemos que o modelo de saúde na rede básica tem o predomínio do pronto-atendimento em suas Unidades Sanitárias. A atividade central é a consulta médica, havendo atividades de vacinação, suplementação alimentar, atendimentos eventuais, pré e pós-consulta, dentre outras, não havendo o desenvolvimento, praticamente de atenção à saúde coletiva.

Estamos de acordo com a autora, pois a dinâmica do atendimento à população nas Unidades Básicas de Saúde de Ribeirão Preto, tem sido o pronto-atendimento, não se fundamenta na história clínica dos pacientes, mas sim no problema e na queixa apresentada, e esse foi um dos pontos destacados por nós.

Neste aspecto o PROASE nas UBSs se contrapunha contra a própria política de Saúde assumida pelo município de Ribeirão Preto, uma vez que o Programa se reestruturou dentro de uma perspectiva de planejamento para o atendimento desses escolares, utilizando como instrumentos de intervenção, diversas atividades programáticas (grupos de pais, de crianças, visitas às escolas, dentre outros) objetivando um efeito sobre a saúde no plano coletivo.

Embora o PROASE tenha sido questionado pela sua verticalidade e tenha sido proposto que o Programa fosse encerrado, assim como qualquer outro Programa da Secretaria Municipal da Saúde dessa mesma natureza, este permaneceu fazendo parte da programação do Plano Diretor de 1994 (RIBEIRÃO PRETO, 1994).

Observamos, no entanto, uma contradição, uma vez que outros Programas verticais foram propostos, no decorrer deste período, aumentando portanto, o número de profissionais existentes de 13 (treze) para 19 (dezenove).

Segundo o "Plano Diretor da Secretaria
Municipal de Saúde" de 1994, as diretrizes políticas garantem no artigo 115, inciso III - "Organizar os Programas de Saúde segundo a realidade epidemiológica e populacional do município, garantindo um serviço de boa qualidade".

Constatamos também, através do documento, que o PROASE tem articulação com o Serviço de Vigilância Epidemiológica da Secretaria Municipal da Saúde, com orientação aos alunos, com retaguarda técnica do Nível Distrital Central. No documento, há uma proposta de trabalho educativo contínuo com professores sobre prevenção e controle de doenças transmissíveis. Observamos também, que o PROASE vem desenvolvendo atividades educativas integradas ao Controle de Vetores da Secretaria da Saúde. Dados referentes ao ano de 1993, ressaltam o trabalho educativo sobre cólera desenvolvido na comunidade pelo PROASE, Unidades de Saúde e Vigilância Epidemiológica.

Em 1993, nas atividades coletivas destinadas às instituições da comunidade, o PROASE se destacava dos demais setores, com um contingente de 657 atividades atingindo uma população de 20.137 habitantes. Outras atividades educativas coletivas destinadas a funcionários da própria Secretaria, bem como de outras Secretarias do Governo Municipal (Educação, Bem Estar Social) se distinguiam dos outros setores, com um total de 190 funcionários atingidos (RIBEIRÃO PRETO, 1994, p.40).

Atualmente, vem se discutindo em âmbito da Secretaria Municipal de Saúde, o modelo existente que se caracteriza pela direção centralizada de várias atividades e Programas que não se integram com outras ações afins, mesmo quando realizados na mesma área geográfica. Outra questão que vem sendo discutida, é o encaminhamento da proposta Reforma Administrativa da Secretaria Municipal da Saúde e que, esta, não se concretizou por falta de viabilidade política, criando um impasse que impede o desenvolvimento da Secretaria Municipal de Saúde. De outro lado, a necessidade de desenvolver Programas e Serviços colide com a limitação dos recursos disponíveis para novas contratações.

Essas questões vêm sendo levantadas pelo atual Secretário Municipal da Saúde, e tudo isso leva a necessidade de repensar a estrutura e o nosso modelo de organização e trabalho. Ressalta, que o vínculo vertical impede a integração dessas atividades e serviços com outros semelhantes que se desenvolvem (organizam, planejam e decidem) no distrito. Acrescenta, ainda, que a Reforma Administrativa da Secretaria Municipal da Saúde de ir proporcionar a efetiva descentralização da administração das atividades e Programas permiti a sua integração na UBSs e UBDSs. A proposta é que se discuta a relação entre níveis Central e Distrital e a divisão de atribuições e competências implantando o conceito de Distritais Sanitários (ROCHA, 1994).

Constatamos nessas primeiras reflexões sobre a 
trajetória do PROASE, que este ao longo de três Governos vem procurando discutir e participar efetivamente junto à Secretaria Municipal da Saúde e esta verticalidade é decorrente da própria política dos dois primeiros governos e do próprio Sistema de Saúde. É necessário uma mudança política na própria Secretaria Municipal da Saúde para que se busque o modelo que venha contribuir para um melhor funcionamento desta.

\section{THE PRIMARY SCHOOL HEALTH CARE PROGRAM AT THE MUNICIPALITY OF RIBEIRÃO PRETO}

The present article reports on the trajectory of the Primary School Health Care Program (PROASE) at the municipality of Ribeirão Preto and describes some reflections about this proposal.

KEY WORDS: school health, program, school education

\section{EL PROGRAMA DE SALUD ESCOLAR EN EL MUNICIPIO DE RIBEIRÃO PRETO}

El presente estudio relata el trayecto del Programa de Atención Primaria de Salud Escolar (PROASE) en el municipio de Ribeirão Preto y trae algunas reflexiones sobre esta propuesta.

TÉRMINOS CLAVES: salud escolar, programa, educación escolar

\section{REFERÊNCIAS BIBLIOGRÁFICAS}

\section{ALMEIDA, M.C.P. O trabalho de enfermagem e a} sua articulação com o processo de trabalho em saúde coletiva: rede básica de saúde em Ribeirão Preto. Ribeirão Preto, 1991. 297p. Tese (LivreDocência) - Escola de Enfermagem de Ribeirão Preto, Universidade de São Paulo.

02. BRASIL. Constituição, 1988. Constituição: República Federativa do Brasil. Brasília: Senado Federal, 1988.

03. CAMPOS, G.W.S. Modelos de assistências e unidades básicas de saúde: um elemento para debate. In: SOUZA, C. et al. Planejamento sem normas. São Paulo: HUCITEC, 1989. p.53-60.

04. COLLARES, C.A.L.; MOYSÉS, M.A.A. O renascimento da saúde escolar legitimando a ampliação do mercado de trabalho escolar. In: CENTRO DE ESTUDOS EDUCAÇÃO E SOCIEDADE (org.). O sucesso escolar: um desafio pedagógico. Campinas: Papirus, 1992. p.23-29.(Cadernos CEDES, 28).

05. CONFERENCIA NACIONAL DE SAÚDE, 8. Anais. Brasília: Centro de Documentação do Ministério da Saúde, 1996.

06. FERRIANI, M.G.C. A inserção do enfermeiro na saúde escolar. São Paulo: EDUSP, 1991. (Coleção Campi, v.3).

07. FERRIANI, M.G.C.; CANO, M.A.T.; VALLE, E.R.M.; RAMOS, P.M. Histórico da saúde escolar: visão global dos serviços de saúde escolar no país. Rev. Bras. Saúde Esc., v.1, n.3/4, p.1420, 1990 .
08. FERRIANI, M.G.C.; CANO, M.A.T. Proposta do PROASE - Plano Diretor de Saúde - 1992. São Paulo / Apresentado à Secretaria Municipal da Saúde de Ribeirão Preto e Escola de Enfermagem de Ribeirão Preto-USP, 1992. 28 p. (mimeografado)

09. HARADA, J. Avaliação das atividades médicoassistenciais do programa de saúde escolar numa Unidade Básica de Saúde no Embú. São Paulo, 1993. 108p. Dissertação (Mestrado) Escola Paulista de Medicina.

10. LIMA, G.Z. Saúde escolar. Perspectivas de desenvolvimento. In: CENTROS DE ESTUDOS EDUCAÇÃO E SOCIEDADE (org.). Fracasso escolar: uma questão médica. São Paulo: Cortez, 1986. p.55-61. (Cadernos CEDES).

11. MERHY, E.E. Brasil pós-64: financiamento e modelos dos serviços de saúde. In: CAMPOS, G.W.S.; MERHY, E.E.; NUNES, E.D. Planejamento sem normas. São Paulo: HUCITEC, 1989. p. 61-112.

12. MISHIMA, S.M. et al. Recursos humanos na implantação das ações integradas de saúde no município de Ribeirão Preto. Visão da equipe de enfermagem. Saúde Pública, Rio de Janeiro, v.6, n. 4, p. 40-9, jan./mar. 1990.

13. NEMES, M.I.B. Ação programática em saúde: recuperação histórica de uma política de programação. In: SHARAIBER, LB. (org.) Programas em saúde hoje. São Paulo: Hucitec, 1990. p. 65-116.

14. PATTO, M.H.S. A produção do fracasso escolar. Histórias de submissão e rebeldia. São Paulo: T.A. Queiroz, 1990. 385p.

15. RIBEIRÃO PRETO. Prefeitura Municipal. Lei $n^{\circ}$ 4476 de 26 de abril de 1984 
16. RIBEIRÃO PRETO. Secretaria Técnica da CIMS. Proposta de reestruturação de Unidades de Saúde. Ribeirão Preto, julho 1986. 4p. (mimeografado).

17. RIBEIRÃO PRETO. Secretaria Municipal da Saúde. Equipe Técnica. Plano Diretor de Saúde do Município de Ribeirão Preto - 1991. Ribeirão Preto, Secretaria Municipal da Saúde, 1991. (mimeografado).

18. RIBEIRÃO PRETO. Secretaria Municipal da Saúde. Equipe Técnica. Plano Diretor de Saúde do Município de Ribeirão Preto - 1994. Ribeirão Preto: Secretaria Municipal da Saúde, 1994. 56p. (mimeografado).
19. ROCHA, J.S.Y. Transformação do modelo assistencial: diretrizes para a reforma administrativa da Secretaria Municipal de Saúde. Ribeirão Preto, 1994. 1p. (mimeografado).

20. SILVA, G.B. Enfermagem profissional: análise crítica. São Paulo: Cortez, 1986. 143p.

21. SCHRAIBER, L.B. (org.) Programação em saúde hoje. São Paulo: HUCITEC, 1990. 226p.

22. TANAKA, O.Y. A municipalização dos serviços de saúde no Estado de São Paulo. Saúde Deb., v. 33, p. 73, 1991. 